\title{
Erratum to: Dissecting chromatin interactions in living cells from protein mobility maps
}

\author{
Fabian Erdel • Katharina Müller-Ott • \\ Michael Baum • Malte Wachsmuth • \\ Karsten Rippe
}

Published online: 6 April 2011

(C) Springer Science+Business Media B.V. 2011 areas as shown elsewhere (Gröner et al. 2010). Therefore Table 2 should read as given below.

The footnote $d$ in the caption of Table 2 has to be changed accordingly to read "The 1D-FCS data were acquired with the STFM (Fig. 4b) (Heuvelman et al. 2009; Baum, Erdel, Müller-Ott, Wachsmuth and Rippe, unpublished)". Also the referring statement in the text on page 111 "For HP1 a comparison between FRAP, RICS, pFCS, 1D-FCS, and 2D-FCS is made in Table 2 and Fig. 4" should read "For HP1 a comparison between FRAP, RICS, pFCS, and 1D-FCS is made in Table 2 and Fig. 4".

On page 106, in the section "FCS with plane excitation and detection", the statement "This setup is referred to here as 2D-FCS. It was recently introduced to conduct first mobility measurements of fluorescent beads with ms time resolution (Wohland et al., 2010) and fluorescent proteins with $\mu$ s time resolution inside living cells or tissues (Capoulade et al. 2010)." should read "This setup was recently introduced to conduct mobility measurements of fluorescent beads with $\mathrm{ms}$ time resolution inside living cells or tissues (Wohland et al., 2010)."

In the caption of Fig. 4, the statement: "For HP1 the spatial/temporal resolution associated with RICS is not sufficient. This issue can be addressed by using a 2D-FCS setup in which light sheet illumination is 
Table 1 Experimental parameters of fluorescence fluctuation methods

\begin{tabular}{llllll}
\hline Method & Spatial resolution & Temporal resolution & $D\left(\mu \mathrm{m}^{2} \mathrm{~s}^{-1}\right)$ & Concentration & References \\
\hline 1D-FCS & $200 \times 380 \times 700 \mathrm{~nm}$ & $15 \mu \mathrm{s}$ & $>0.1$ & $\mathrm{nM}-\mu \mathrm{M}$ & Heuvelman et al. 2009 \\
$2 \mathrm{D}-\mathrm{FCS}$ & $300 \times 300 \times 100 \mathrm{~nm}$ & $1 \mathrm{~ms}$ & $>0.1$ & $\mathrm{nM}-\mu \mathrm{M}$ & Kannan et al. 2007 \\
& $400 \times 400 \times 1400 \mathrm{~nm}$ & $2-6 \mathrm{~ms}$ & $>0.1$ & $\mathrm{nM}-\mu \mathrm{M}$ & Wohland et al. 2010 \\
\hline
\end{tabular}

Table 2 Fluctuation microscopy measurements of HP1

\begin{tabular}{llll}
\hline Technique & \multicolumn{2}{l}{$D_{\text {app }}\left(\mu \mathrm{m}^{2} \mathrm{~s}^{-1}\right)$} & \\
\cline { 2 - 4 } & Cytoplasm & Euchromatin & Heterochromatin \\
\hline FRAP $^{\mathrm{a}}$ & $\mathrm{ND}$ & $0.003-0.43$ & $0.0006-0.49$ \\
RICS $^{\mathrm{b}}$ & $7 \pm 3$ & $0.2-0.4$ & $0.2-0.4^{\mathrm{c}}$ \\
pFCS & $23-26$ & $7.7 \pm 0.8^{\mathrm{c}}$ & $3.9 \pm 0.9^{\mathrm{c}}$ \\
D-FCS $^{\mathrm{d}}$ & $\mathrm{ND}$ & $7.9 \pm 0.8^{\mathrm{c}}$ & $3.4 \pm 0.4^{\mathrm{c}}$ \\
\hline
\end{tabular}

combined with detection of intensity fluctuations on an EMCCD (Capoulade et al. 2010; Wohland et al. 2010)." should be removed since no 2 D-FCS data for HP1 were available.

The reference "Capoulade et al. 2010" is no longer cited in the text and should therefore be removed from the reference list.

The authors regret any confusion these errors may have caused. 